\section{POLÍTICAS CURRICULARES E EJA: a luta pela significação de gênero no contexto da prática docente}

CURRICULAR POLICIES AND EJA: the struggle for gender meaning in the context of teaching practice

\author{
Rafael Ferreira de Souza Honorato \\ Tarcísio Duarte da Costa \\ Maria Zuleide da Costa Pereira ${ }^{3}$
}

\begin{abstract}
Resumo: Este artigo discorre sobre os resultados de uma pesquisa realizada no curso de especialização lato sensu em Gênero e Diversidade na Escola (GDE) na Universidade Federal da Paraíba, sob responsabilidade do Núcleo Interdisciplinar de Pesquisa e Ação sobre Mulher e suas Relações de Sexo e Gênero. A pesquisa objetivou analisar como as relações de gênero estão expressas no currículo dos Centros Estaduais de Educação de Jovens e Adultos (CEJAs) da Cidade de João Pessoa/PB e por alunos/as e docentes do $3^{\circ}$ segmento da EJA. No desenvolvimento desta análise, serão utilizados os argumentos do Ciclo de Políticas, com base nos estudos de Stephen Ball, Richard Bower e Anne Gold (1992) e Stephen Ball (1994), através dos estudos de Jefferson Mainardes (2006), Jefferson Mainardes e Silvana Stremel (2015) e Alice Casimiro Lopes e Elizabeth Macedo (2011). Metodologicamente, desenvolveram-se análises por uma perspectiva qualitativa, com viés etnográfico. Para isso utilizamos observação participante, notas de campo e documentos como coleta de dados. Concluímos que existe um processo de recontextualização das formas que as políticas curriculares estão (des) construindo as relações de gênero na EJA, fenômeno que ocorre no contexto da prática, através das interpretações e posicionamentos críticos evidenciados nas atitudes dos/as docentes e alunos/as da escola campo.
\end{abstract}

Palavra-chave: Políticas Curriculares. Currículo. Gênero. EJA.

\section{INTRODUÇÃO}

Esta pesquisa foi desenvolvida no âmbito do Curso de Especialização Lato Sensu em Gênero e Diversidade na Escola (GDE), ofertado pela Universidade Federal da Paraíba, Campus I, sob

\footnotetext{
${ }^{1}$ Doutorando em Educação do Programa de Pós-graduação em Educação da Universidade Federal da Paraíba. Email: <rafaelhono@gmail.com>.ORCID: <http://orcid.org/0000-0002-6196-0211>

${ }^{2}$ Mestre em Educação pela Universidade Federal da Paraiba. E-mail: <t_duarte@hotmail.com>

3 ProfessoraTitular do Centro de Educação da Universidade Federald a Paraíba e docente do quadro permanente do Programa de Pós-graduação em Educação. E-mail: <mzul@uol.com.br>. ORCID: <http://orcid.org/0000-0002-89809302>
} 
responsabilidade do Núcleo Interdisciplinar de Pesquisa e Ação sobre Mulher e Relações de Sexo e Gênero (NIPAM). Desse modo, nesta pesquisa, objetivamos analisar os modos como as relações de gênero estão expressas no currículo dos Centros Estaduais de Educação de Jovens e Adultos (CEJAs), na cidade de João Pessoa/PB, e como essas relações são vivenciadas por alunos(as) do Ensino Médio/EJA nas práticas docentes. Tal objetivo tenta evidenciar como estão sendo construídas, vividas e estruturadas as relações de gênero (masculinidades e feminilidades) no currículo dessa modalidade de ensino e na prática dos(as) participantes (discentes e docentes) inseridos nos CEJAs.

Metodologicamente, a pesquisa envolveu a análise dos documentos produzidos pelo Ministério da Educação, pela Secretaria de Estado de Educação/PB e do Projeto Político-Pedagógico (PPP) da escola campo da pesquisa. O trabalho de campo se deu em um dos três CEJAs de João Pessoa/PB, a partir das seguintes estratégias para coleta dos dados: observação de uma aula, da sala de professores(as) e dos espaços comuns da escola (pátio, corredores, entrada e sala dos professores); entrevistas semiestruturadas com 05 (cinco) docentes da escola campo, que foram gravadas e posteriormente transcritas, e que possuíam três blocos: a) Formação e trajetória profissional, b) currículo e sua construção e c) sobre como pensam as questões de gênero no currículo; por fim, solicitamos o PPP para análise.

A escolha da escola se deveu ao fato de que ela é a única no município de João Pessoa, que oferta apenas a modalidade de Educação de Jovens e Adultos, presencialmente e a aplicação de exames. Já a escolha dos(as) docentes se deu pela disposição em participar da pesquisa; do quadro de quinze docentes que trabalham no turno da noite ministrando aulas na modalidade presencial, apenas cinco desse total se disponibilizaram a participar, assinando o Termo de Consentimento Livre e Esclarecido (TCLE), ficando acordado que seus nomes seriam mantidos em sigilo o que nos levou apenas a enumerá-los/as. Todavia, entre eles e elas tínhamos docentes do sexo masculino, professores dos componentes curriculares química e inglês; do sexo feminino, artes, sociologia e geografia. As entrevistas foram realizadas na própria instituição de ensino no horário antes das aulas.

Para alcançar o objetivo proposto, fez-se uso das teorizações de Ball, Bower e Gold (1992) e Ball (1994), pois esses autores colocam os processos micropolíticos em evidência, reforçando a necessidade de relacionar as instâncias macro e micro nas pesquisas do campo curricular.

Os estudos de Ball, Bower e Gold (1992) e Ball (1994), explicitados a partir da produção contínua de políticas, por meio do ciclo de políticas, serviram de auxílio na compreensão de como os processos de transferência das políticas se constituem de um contexto para outro, ou no momento em que os discursos pedagógicos se fundem. Esses processos envolvem relações de poder que não são fixas e que acabam sendo descontextualizadas, (re)significando sentidos que tinham a intenção de serem fixos, tais como: ensino, aprendizagem, qualidade, gênero, currículo, entre outros. Desse modo, são recontextualizados em novos sentidos que dão origem a novos discursos e textos na micropolítica (LOPES; MACEDO, 2011). Ball (1994) define a micropolítica como o processo que liga duas facetas básicas, contraditórias e inexoráveis da vida das organizações: o conflito e o controle, este entendido aqui como a eliminação ou a prevenção do conflito.

As análises desta pesquisa sobre as políticas curriculares, o currículo e o gênero seguem as matrizes conceituais de autores e autoras nacionais com projeção internacional, tais como: Carvalho (2003), Lopes (2006), Mainardes (2006), Oliveira, Teixeira e Campos (2011), Oliveira e Paiva (2009), Pereira (2009), entre outros(as) indispensáveis à constituição das nossas análises.

A iniciativa de analisar as categorias currículo e gênero, tomando como contexto a EJA (Ensino Médio), além de inovadora, é um desafio, levando em consideração as poucas produções que apreendem esse mesmo esforço. Em levantamento feito para a elaboração deste artigo, nos anais da $33^{\mathrm{a}}$ e $34^{\mathrm{a}}$ reuniões da Associação Nacional de Pós-Graduação e Pesquisa em Educação (ANPED); nos Grupos de Trabalho 12 (GT Currículo), 18 (GT Educação de Pessoas Jovens e Adultas) e 23 (GT Gênero, Sexualidade e Educação) não se constataram pesquisas similares. Quando há a ocorrência dos descritores currículo e gênero, o contexto no qual os textos foram produzidos difere da EJA. Tal constatação dá a este estudo uma relevância, por tentar colocar no cenário nacional e até internacional uma problemática pouco explorada. 
A partir do estudo realizado, percebeu-se a existência de um processo de recontextualização das formas como as políticas curriculares estão (des)construindo as relações de gênero na EJA. Esse fenômeno ocorre no contexto da prática docente, através das interpretações e posicionamentos críticos evidenciados nas atitudes dos(as) docentes e alunos(as) da escola campo desta pesquisa. Destarte, confirmou-se a teoria de Ball (1994), que aponta para a intervenção dos(as) profissionais, no contexto da prática, como um elemento de (re) significação das políticas educacionais.

\section{O CONTEXTO DA PRÁTICA NO CICLO DE POLÍTICAS: dos efeitos às estratégias políticas}

O Ciclo de Política, com forma mais ampla, é uma denominação de um processo utilizado por teóricos ingleses, como Stephen Ball, Richard Bowe e With Gold (1992), para compreender a constituição das Políticas Educacionais, levando em consideração as relações entre os contextos macro e o micropolíticos, bem como as ações dos(as) profissionais da educação, entre outros(as) que lidam com as políticas. A abordagem designada pelos autores visa a entender de forma mais minuciosa como acontece a criação e efetivação das políticas na prática. Dessa forma, entende-se que esse ciclo concentra seu foco desde o processo de formação do discurso político ${ }^{4}$ até a (re)interpretação dos sujeitos que o implementam nos espaços escolares.

Assumem-se como definições para este processo as afirmações de Mainardes (2006, p. 49), quando diz:

Essa abordagem destaca a natureza complexa e controversa da política educacional, enfatiza os processos micropolíticos e a ação dos profissionais que lidam com as políticas no nível local e indica a necessidade de se articularem os processos macro e micro na análise de políticas educacionais.

O Ciclo de Políticas está dividido em três contextos, a saber: o Contexto de Influência, o Contexto de Produção de Textos e o Contexto da Prática. No primeiro contexto, o foco está nos discursos hegemônicos, ou seja, a análise fixa os esforços em compreender quais são os interesses disputados pelos grupos para influenciar as finalidades e definições sociais da educação. Esse processo de influência acontece através dos livros, artigos, revistas, conferências e exposição de ideias nos espaços políticos e acadêmicos.

O Contexto de Produção dos Textos se assemelha bastante ao contexto anterior. Mas diferente do contexto da influência, que está mais ligado aos interesses ideológicos e dogmáticos, a produção dos textos está estreitamente relacionada aos interesses do público em geral. Porém, os propósitos desses dois contextos são bem similares, pois buscam, através dos meios de comunicação, a veiculação de suas ideias. A linguagem política se apresenta como textos, documentos legais, pronunciamentos oficiais nas mídias e são frutos dos embates dos grupos que disputam a produção e a reprodução das políticas. Todavia, Mainardes (2006, p. 52) chama a atenção para o fato de que "os textos precisam ser lidos com relação ao tempo e ao local específico de sua produção".

O Contexto da Prática para Ball, Bowe e Gold (1992) é onde as Políticas Educacionais estão sujeitas à reinterpretação e criação, produzindo efeitos e consequências que podem representar modificações significativas na Política original.

[...] os profissionais que atuam no contexto da prática [escolas, por exemplo] não enfrentam os textos políticos como leitores ingênuos, eles vêm com suas histórias, experiências, valores e propósitos [...]. Políticas serão interpretadas diferentemente uma vez que histórias, experiências, valores, propósitos e interesses são diversos. A questão é que os autores dos textos políticos não podem controlar os significados de seus textos. Partes podem ser rejeitadas, selecionadas, ignoradas, deliberadamente mal entendidas, réplicas podem ser

\footnotetext{
${ }^{4}$ Entende-se por discurso político, a partir dos estudos de Ball (1994), o currículo oficial que é instituído pelos textos das políticas nacional e locais.
} 
superficiais etc. Além disso, interpretação é uma questão de disputa. Interpretações diferentes serão contestadas, uma vez que se relacionam com interesses diversos, uma ou outra interpretação predominará, embora desvios ou interpretações minoritárias possam ser importantes (BALL; BOWE; GOLD, 1992, p. 22 apud MAINARDES, 2006, p. 53).

Neste contexto, a abordagem proposta pelos autores assume que os(as) docentes e demais profissionais ocupam um espaço no processo de (re)interpretação das políticas educacionais. Assim, as singularidades (pensamentos e crenças) são fatores importantes no processo de criação e implementação das políticas (MAINARDES, 2006).

Entretanto, na tentativa de potencializar o Ciclo de Políticas, em 1994, Ball expandiu o Ciclo, inserindo mais dois contextos: o Contexto dos Resultados/Efeitos e o Contexto da Estratégia Política. Ambos os contextos, segundo Oliveira, Matheus e Lopes (2011), são ainda pouco usados nas pesquisas sobre currículo. O que chama a atenção para o uso do quarto contexto - O Contexto dos Resultados/Efeitos - é o fato destacado por Mainardes (2006) de que este se preocupa com os assuntos inerentes aos temas de justiça, igualdade e liberdade individual. É nesse momento que as políticas devem ser analisadas como causadoras de efeitos na vida e ação dos sujeitos. No caso, as políticas são analisadas a partir dos impactos que podem causar nas relações de desigualdades que possam existir na prática.

$\mathrm{E}$, ainda, o último contexto se mostra importante nas análises desta pesquisa, uma vez que o contexto da estratégia política possibilita a "[...] identificação de um conjunto de atividades sociais e políticas que seriam necessárias para lidar com as desigualdades criadas ou reproduzidas pelas políticas investigadas" (MAINARDES, 2006, p. 55).

A escolha por esse processo de análise deve-se à superação dos fatores referentes à simplicidade e linearidade de outras formas de analisar as políticas. O Ciclo de Políticas é uma abordagem complexa que apresenta contribuições positivas para esta pesquisa, uma vez que considera o processo político como multifacetado e dialético, partindo das relações entre a macro e a micropolítica.

Nos estudos de Mainardes (2015) há um destaque quando ele coloca que Ball, Bower e Gold (1992) redefinem o ciclo de políticas como contínuo, composto por três contextos principais inter-relacionados, livres de uma condição temporal e/ou sequência sem aspectos de linearidade. $O$ autor apresenta, ainda, como aspectos, as múltiplas arenas, lugares e grupos de interesses e as diferentes formas com que estes podem se apresentar em cada contexto com suas disputas e embates. Dessa forma, para analisar a trajetória da política proposta neste estudo, mesmo com uma ênfase no contexto da prática, mencionamse os cinco contextos do ciclo de políticas.

No próximo tópico faremos a análise das políticas nacionais e locais e como essas incorporam à temática gênero nos seus textos.

\section{CURRÍCULO E GÊNERO NA EJA: o que dizem os textos oficiais do MEC e SEE/PB}

Para iniciarmos as nossas análises é necessário compreender que o gênero é compreendido neste estudo a partir de Carvalho (2003) como uma categoria que se refere às relações sociais desiguais de poder entre homens e mulheres que são o resultado de uma construção social do papel do homem e da mulher a partir das diferenças sexuais. É a partir dessa definição que percebemos um vínculo com a definição de currículo de Pereira (2009), segundo a qual este é uma rede de significações, que ao longo do trajeto leva em consideração o tempo e o espaço. Neste, promove a (re)significação, ou seja, produz novos sentidos das demandas sociais.

A pesquisa nos levou às leis aqui analisadas - Lei de Diretrizes e Bases da Educação Nacional (LDB) e Diretrizes Curriculares para a Educação de Jovens e Adultos - que são frutos de um processo de redemocratização do país que teve início na década de 1980. A efetivação desses documentos no cenário nacional aconteceu na década de 1990, com a promulgação da Lei n 9394/96, que tinha sido dada, no art. 22 da Constituição Federal de 1988, como sendo de responsabilidade da União.

A LDB, em seu art. $2^{\circ}$, instaura os princípios e fins da Educação Nacional, destacando que a educação, "nos princípios de liberdade e nos ideais de solidariedade humana, tem por finalidade o pleno 
desenvolvimento do educando, seu preparo para o exercício da cidadania e sua qualificação para o trabalho" (BRASIL, 2009). É nesse momento que estão postas implicitamente as vertentes de formação do educando como um sujeito, respeitando os princípios de igualdade de direitos entre eles.

Afirmações como essa são registros da força que a educação pode ter na superação ou perpetuação de desigualdades, visto que existe a possibilidade de através dela acontecer a reprodução ou superação de valores, conhecimentos, princípios etc. Assim, cada vez mais se mostram necessárias as discussões sobre diversidade, gênero e sexualidade no currículo dos diferentes níveis e modalidades de ensino, como forma de desconstruir estereótipos.

A Lei $n^{\circ} 9394 / 96$, em seu art. $3^{\circ}$, defende uma educação nacional respaldada em princípios gerais de liberdade, pluralismo e tolerância. No tocante às questões de gênero, estas se encontram respaldadas na LDB em termos gerais através do art. $3^{\circ}$ que estabelece os princípios da Educação Nacional. Mas essa posição mais genérica se dá devido ao fato de esse documento ser um orientador das demais políticas educacionais que se desdobram nos diferentes níveis e modalidades da Educação Básica (BRASIL, 2014).

Em 5 de julho de 2000, foram elaboradas as Diretrizes Curriculares para a Educação de Jovens e Adultos, resolução CNE/CEB 11/2000. Tais diretrizes são resultantes da Declaração de Hamburgo de 1997 (da qual o Brasil é signatário), onde ficou instituído que a não oferta dessa modalidade acarreta em crime de não responsabilidade. Assim, a resolução supracitada tenta garantir regulamentar de forma mais precisa as atribuições, configurações e responsabilidade da EJA com os(as) Jovens e Adultos(as). Todavia, o texto não trata em suas linhas sobre como serão abordadas as questões de gênero na modalidade da EJA. Esse se torna mais um documento que estabelece princípios gerais no parágrafo único do Art. 5, entre eles, a equidade, a diferença e a proporcionalidade, que buscam garantir oportunidades ao acesso e os conhecimentos compartilhados no processo educacional.

Observar que o gênero e o trato pedagógico com essa categoria em sala de aula sempre são compreendidos nas políticas em termos gerais, e até mesmo genéricos, leva-nos a perceber que o currículo oculto é o terreno aonde vem se estabelecendo o trabalho com o tema. Isso nos parece uma estratégia política, o que faz com que a inserção do tema fique a critério dos sujeitos (docentes) e suas interpretações dos textos das políticas, o que por sua vez não é bem analisado na formação inicial, e muito menos na continuada. Quando se trata da EJA, ainda notamos uma grande lacuna temporal entre a Constituição que já garantia a necessidade dessa modalidade e as DCNs, uma década para tentar regulamentar uma modalidade de ensino não nos parece algo que venha ressaltar a importância que possa ter.

Quando se chega às políticas estaduais estabelecidas pela SEE/PB, encontra-se nas Diretrizes Operacionais para o Funcionamento das Escolas da Rede Estadual de Ensino de 2015, Portaria $N^{\circ}$ 1.115/2014, um documento que orienta o funcionamento das escolas, desde a construção de suas propostas pedagógicas, cujos princípios são intimamente relacionados às políticas curriculares nacionais produzidas pelo MEC. De toda forma, o gênero é abordado em termos gerais e o documento apenas recomenda que os Projetos Político-Pedagógicos (PPPs) das instituições sejam elaborados considerando alguns aspectos, entre eles, a "valorização e promoção dos Direitos Humanos, mediante temas relativos a gênero, identidade de gênero [...]” (PARAÍBA, 2014, p. 29).

A questão que se coloca neste estudo é a falta de uma equipe pedagógica na escola que possa auxiliar na construção do PPP, visto que no quadro de funcionários da escola não existe nenhum(a) pedagogo(a). Nesse caso, qual será a concepção de gênero e quais as relações de gênero que vão estar presentes em tais PPPs? A falta de formação dos(as) profissionais para lidar com a questão de gênero é mais uma forma de fazer permanecer essa estrutura social, em que o homem e a mulher possuem papéis diferentes na sociedade, e a escola é um dos espaços de reprodução desse papel.

Essa fragilização da temática de gênero, sofrida na construção dos documentos que orientam a Educação Nacional, especificamente a EJA (Diretrizes Curriculares Nacionais, Projetos PolíticoPedagógicos), a partir da LDB, é mais uma evidência da timidez que as políticas voltadas à Educação de Jovens e Adultos possuem. Esse processo de desvalorização é histórico, o que chama a atenção para o 
fato de que a cada dia a diversidade desses(as) jovens e adultos(as) nas escolas que ofertam essa modalidade é maior, o que traz a essas salas de aula uma diversidade que vem sendo negada (OLIVEIRA; TEIXEIRA; CAMPOS, 2011).

No cenário nacional e internacional, existem espaços onde são pensadas essas políticas para a EJA, mas parece que os esforços acadêmicos não estão sendo suficientes para construir políticas mais eficazes. No que diz respeito à efetivação dessas políticas na escola que oferece a EJA, é o que se percebe, principalmente, nos CEJAs de João Pessoa/PB. No Documento Nacional Preparatório para a realização da VI Conferência Internacional Sobre Educação de Adultos (CONFITEA), realizada em 2010 em Belém, Pará, Brasil, o texto destacava a diversidade e os desafios que a EJA enfrenta para lidar com as temáticas, destacando-se gênero, diversidade, religiosidade, sexualidade, entre outras:

A EJA é também espaço de tensionamento e aprendizagem em diferentes ambientes de vivências que contribuem para a formação de jovens e adultos como sujeitos da história. Nesses espaços, a EJA volta-se para um conjunto amplo e heterogêneo de jovens e adultos oriundos de diferentes frações da classe trabalhadora. Por isso, é compreendido na diversidade e multiplicidade de situações relativas às questões étnico-racial, de gênero, geracionais; de aspectos culturais e regionais e geográficos; de orientação sexual; de privação da liberdade; e de condições mentais, físicas e psíquicas - entendida, portanto, nas diferentes formas de produção da existência, sob os aspectos econômico e cultural. Toda essa diversidade institui distintas formas de ser brasileiro, que precisam incidir no planejamento e na execução de diferentes propostas e encaminhamentos na EJA (BRASIL, 2009, p. 28).

Estudos como os de Oliveira e Paiva (2009), Paiva (2009) e Haddad e Di Pierro (2000) demonstram que as práticas que se desdobram no cotidiano escolar da EJA ressaltam que os sujeitos inseridos nesse contexto não são definidos apenas pela diferença de idade ou geracionalidade, mas que eles têm em comum o fato de terem sido excluídos do ensino regular, aspecto esse que também se pode destacar como cultural, ao observarmos sua construção histórica e a continuidade desse processo nos dias atuais.

Do mesmo modo, discutir sobre um currículo para a EJA leva à necessidade de se buscar refletir sobre a configuração dessa modalidade de ensino no atual contexto histórico, político, econômico, social etc., a fim de vislumbrar os novos sentidos que estão sendo construídos para as práticas e os conceitos, em meio a essas intensas mudanças (VALE; OLIVEIRA, 2010). Destaca-se, entre esses novos conceitos e práticas, a própria concepção de EJA, que surge no Ensino Médio/EJA. Para os sujeitos dessa modalidade, estar na escola é mais do que querer ser alfabetizado; hoje o que se destaca é a busca por cursos profissionalizantes, técnicos e até superiores.

Vista essa fragilidade nas políticas para a EJA, o próximo tópico busca expor como foram percebidas tais questões nas práticas discursivas dos sujeitos que cursam essa modalidade de ensino, especificamente os do Ensino Médio.

\section{CURRÍCULO E GÊNERO: as recontextualizações na prática docente e discente}

$\mathrm{Na}$ investigação da política curricular aqui apresentada, foi selecionado como uma das fontes o Projeto Político-Pedagógico (PPP). A análise desse documento permitiu dizer, inicialmente, que a concepção de currículo nele privilegiada é a ideia de um currículo único, o que direciona para a compreensão da escola como um espaço de transmissão da cultura erudita, sendo esse processo o único caminho para a aceitação dos sujeitos nos círculos sociais, fazendo com que o discurso pedagógico, que se constitui de forma mais ampla do que o currículo, aponte para a defesa de uma cultura comum (LOPES, 2006).

Tal aspecto preliminar nos lembra Foucault (1987), quando destaca que a homogeneidade é buscada pelas vias do poder de regulamentação em busca de um corpo social; todavia, essa busca também segrega e individualiza, resultando no processo em que dentro "[...] de uma homogeneidade que é a regra [o poder da norma] introduz, como um imperativo útil e resultado de uma medida, toda a 
gradação das diferenças individuais" (FOUCAULT, 1987, p. 154). É assim que no currículo da escola campo as questões de gênero são apresentadas, hierarquizadas e posicionadas.

Não se constitui, portanto, no PPP, um sentido para o currículo e/ou diálogo sobre as teorias, e por consequência nem para o gênero, entre outros conceitos que são inerentes à constituição de uma proposta política e pedagógica, tais como: didática, avaliação, ética etc. Encontra-se, nas análises do PPP, a concepção de educação que a escola segue:

[...] acreditar na educação como ferramenta de transformação na vida do educando é uma máxima. Máxima que toda a comunidade escolar se predispõe a atuar de maneira efetiva e ética em suas ações cujo objetivo maior é fazer da educação, no meio em que estamos inseridos, um local de refúgio, conhecimento, esperança, diálogo e, sobretudo, amor. "Não há diálogo, diz Freire (2011, p. 110), porém, se não há um profundo amor ao mundo e aos homens" (PPP, 2015, p. 11).

Tal forma de pensar a educação coloca em evidência questões pertinentes ao diálogo, questões que vêm sendo negligenciadas, entre elas o gênero, o que gera um posicionamento em direção ao que é considerado como padrão e ideal, assim produzindo discursos atravessados por relações de poder (FOUCAULT, 1987). Tais, relações têm sido estabelecidas para uma maior valorização social de homens heterossexuais (BUTLER, 2003).

Pela falta de um desenho curricular construído coletivamente e em comum acordo as práticas pedagógicas, enfrentam dificuldades cotidianas, nas aulas e nos demais espaços. Além da estruturação da proposta política e pedagógica para a escola, na fala dos(as) docentes, fica evidente a ausência dos(as) profissionais na construção do que deveria ser um projeto coletivo. A professora 1, no bloco das entrevistas, que correspondia à caracterização do perfil do profissional, relatou que estava na escola há um mês e não fez parte de nenhuma reunião para debater o PPP da escola. Já outros dois docentes relataram:

Rapaz sinceramente eu tive a participação mais de telespectador sinceramente, porque a gente tem o, a estrutura do PPP que a gente bem sabe como é construída, a gente tem uma base de documentação de outros colégios, né! Aí a construção ela é, no meu caso mais de telespectador, de observar, de ler e acompanhar, não de criar na prática foi assim né, a gente tem um documento que foi elaborado e a gente se tornou telespectador da elaboração na verdade, eu não acredito que sendo bem sincero não houve uma construção democrática, nesse sentido. Claro que tem muitos fatores que influenciaram né, a questão de tempo, a questão de você sabe como foi (PROFESSOR 2).

Eu vim saber de alguma coisa desse PPP no primeiro momento do projeto escola de valor (PROFESSORA 3).

Vinculada às afirmações acima, os(as) docentes mostraram nas entrevistas uma falta de compreensão sobre o que é uma proposta curricular, dizendo que:

São os conteúdos que vão ser trabalhados, as temáticas, né? as temáticas que vão ser trabalhadas é adequar com a realidade do aluno, né? procurar trabalhar temas relevantes assim que faz parte do cotidiano deles (PROFESSORA 1).

Bom a princípio, aparentemente me parecia até pouco tempo atrás que seria só questão disciplinar mesmo de conteúdo, mas a partir de um certo momento eu começo a perceber que não é só isso tem toda questão extra que vai muito além desde da parte do entendimento do alunado do contexto de vida da comunidade então tem essa questão, tem a, os conceitos que tem sobre as pessoas, sobre o ensino, sobre o aprendizado desse contexto. Então na verdade eu acredito que seja um conjunto de conceitos que deve se estabelecer baseado no ambiente 
naquele ambiente que se vai aplicar educação e a partir dessa visualização se descrever em inúmeras ferramentas e atitudes, desde conteúdos, desde a metodologia né e até de questões burocráticas, por exemplo (PROFESSOR 2).

A organização é cada um, cada funcionário nesse termo né assim, a partir da secretaria tem que ser tudo organizado para poder a escola caminhar, né porque se não for nada organizado nada vai pra frente (PROFESSOR 3).

Como se percebe, este cenário é fruto da falta de uma proposta curricular para o Ensino Médio da EJA, assim como existe para o $1^{\circ}$ e o $2^{\circ}$ segmento, que compreendem os anos iniciais e finais do Ensino Fundamental. Essa carência vem se tornando um desafio para os(as) profissionais que desenvolvem suas atividades na EJA, cuja formação inicial e continuada apresenta inúmeras lacunas.

Nas entrevistas realizadas no bloco que tratava sobre as relações de gênero e fazia uma relação com o papel da escola na (re)produção dos modelos de masculino e feminino, na opinião dos entrevistados e entrevistadas sobre o que a sociedade espera para homens e mulheres, se são coisas diferentes ou não, percebeu-se respostas tímidas e muitas vezes conflituosas em relação aos seus valores pessoais, políticos e religiosos. Os aspectos religiosos surgem das denominações religiosas em que cada um está inserido; entre os(as) entrevistados(as) dois são evangélicos e outros dois são católicos praticantes, o quinto não demonstra ser tão ligado aos dogmas religiosos. Esses aspectos são perceptíveis para nós devido ao nosso tempo de trabalho (quatro anos) no local observado. Mas, em termos gerais, eles(as) elencaram que existem essas determinações diferentes.

Entretanto, ao serem questionados sobre o papel da escola na constituição dessas habilidades e valores diferentes, os(as) professores(as) pouco souberam explicar quais seriam as formas de reforçar ou transformar esses modelos instituídos socialmente. Contudo, faz-se uma ressalva à fala da Professora 4, que elencou como uma dessas formas de reprodução das diferenças o fato de a escola, o estado e o governo, de forma geral, não terem programas assistenciais e complementares para atender os filhos e filhas das alunas(os) que, por não terem com quem deixá-los(as), acabam levando-os(as) até a escola e que isso, muitas vezes, serve de justificativa para a evasão destas(es) alunas(os).

Mas quando questionados(as) se nas aulas eles(as) percebem comportamentos diferenciados entre homens e mulheres quanto à distribuição em sala e ao trabalho em equipe, os(as) professores(as) das áreas de humanas (Artes, Geografia e Sociologia) foram pontuais em afirmar que as mulheres são destacadas como organizadas e estudiosas, enquanto que os homens entram nos grupos para se aproveitar dessas habilidades e, muitas vezes, ficam responsáveis pelas questões financeiras envolvidas na realização das atividades. O único professor da área das exatas disse não ter percebido tais detalhes nas relações interpessoais entre os(as) alunos(as).

Assim como Paraíso (2010, p.18) em suas pesquisas, o currículo que investigamos está imbuído em "um sistema de pensamento generificado que divide, hierarquiza e confina [homens] e [mulheres] em certos espaços". Pensamentos generificados servem de instrumento de classificação dos espaços do masculino ou feminino, atribuindo aos homens características protetivas, financeiramente mantenedores, supostamente mais desinteressados, mas que isso é justificável devido às horas de trabalho para manter a família, entre outros aspectos (PARAISO, 2010).

Como defende Paraíso (2010), a forma generificada de pensar reverbera nas práticas curriculares. Assim, os pensamentos generificados orientam “[...] condutas e práticas nos currículos" (PARAísO, 2010, p. 19). Constatamos tal afirmação durante a observação participativa feita na escola. Vislumbraram-se situações diversas em que a mulher e o homem são tratados de formas diferenciadas, possibilitando dizer que em alguns momentos privilegia e em outros desfavorece os(as) discentes em virtude das questões de gênero. Na sala de aula, um(a) professor(a) não percebe a dificuldade das alunas em estarem em sala com crianças e o acúmulo de trabalhos que elas têm como donas de casa e, muitas vezes, tendo outro trabalho fora, fato esse que garante o aumento da renda familiar e a inserção da mulher no mercado de trabalho, mas vale ressaltar que no caso desse estudo elas ainda estão em profissões ligadas ao trabalho doméstico. Com os homens há um estereótipo formado: sempre a falta de concentração e a preguiça ou até mesmo as questões sexuais (o namoro na escola) que se fazem presentes são colocadas em detrimento dos conteúdos e da aula em si. 
Assim, pensando que o Gênero é "[...] o mecanismo através do qual se produzem e se naturalizam as noções de masculino e de feminino" (BUTLER, 2006, p. 70), o currículo da escola campo contribui com a afirmação e naturalização do papel do homem, bem como com a continuidade de uma sociedade machista e patriarcal. Observamos que faz parte do processo de educação dos meninos a assimilação desse estereótipo onde o homem tem que ser descolado e namorador, acima da mulher e das demais orientações sexuais que fogem dos padrões instituídos pela sociedade, coadunando com a ideia de Butler (2003), em que o gênero como formas de ser é constantemente reiterado por meios de gestos, estilos corporais, forma de vestir e estar no meio, dando a noção de um sujeito com gênero constante (BUTLER, 2003).

O que se vê é uma multiplicidade de contextos sociais, políticos, familiares, culturais, entre outros aspectos, que diferenciam aqueles sujeitos, e que os professores e professoras acabam negligenciando pela falta de um olhar mais crítico e diagnóstico, pois o que se pode destacar como elemento comum entre todos/as é o cansaço. Então, o trabalho pedagógico deve ser direcionado e pensado de forma a incentivar, oferecer oportunidade e possibilidade de permanência e promoção, fazendo dos CEJAs espaços políticos, onde se desdobrem práticas de equidade e não só de reparação política e social.

Não se pode deixar de destacar a fala de um dos docentes nas entrevistas, que talvez traduza alguns dos esforços teóricos em mostrar a relação entre as políticas curriculares e as práticas docentes no que concerne às relações de gênero. Na questão sobre a importância de atividades pedagógicas presentes no currículo da escola para amenizar os aspectos que reproduzem as diferenças de oportunidades entre homens e mulheres, o Professor 2 destacou: "Não, eu acho que é assim, essa é uma pergunta até fácil de responder. Porque é necessário, visivelmente necessário, que é o que ocorre e no ponto de vista prático também. Necessário talvez seja só um debate aí de como fazer, mas que é necessário é".

Então, essa fala culmina na falta de um debate político, educacional, ideológico, até mesmo profissional, sobre quais são as formas de trazer para a EJA soluções para as problemáticas postas nesse espaço. Fingir que a função da EJA é única e exclusivamente reparadora é um equívoco, em meio ao novo paradigma social da comunicação, de uma sociedade grafocêntrica ${ }^{5}$. Em todas as instâncias da sociedade se estabelecem lutas pelo direito à igualdade; essa modalidade de ensino não pode continuar com interesses tão restritos. São as políticas educacionais que podem garantir o direito, mas é nas práticas que esse direito se estabelece de fato.

\section{CONSIDERAÇÕES FINAIS}

Este trabalho, a partir do ciclo contínuo de políticas de Ball, Bower e Gold (1992), buscou compreender como o gênero vem se constituindo nas políticas curriculares para a Educação de Jovens e Adultos. A forma como se deu o andamento desta pesquisa vem da forma como se concebem as políticas, ou seja, como discursos oriundos também da escola e dos sujeitos que a constituem. De acordo com o observado, os discursos que constituem essas políticas são híbridos culturais, não se limitam às vontades do Estado, mas vão além e mantêm uma relação constante com as práticas desenvolvidas pelos sujeitos nos locais dos quais as políticas falam.

As análises que partiram das observações, das entrevistas e dos documentos nacionais, locais e até mesmo da própria escola campo deram subsídios para a realização deste estudo. Percebemos que, mesmo com todos os desafios, adversidades e dificuldades inerentes ao ensino na EJA, há uma pequena, frágil e tímida preocupação dos(as) professores(as) da escola estudada com as problemáticas referentes às relações de poder que emanam das relações de gênero.

Contudo, as relações de gênero presentes na EJA vêm se mostrando como fortes consequências de outros problemas, tais como: evasão das mulheres donas de casa e mães de família por causa da presença dos filhos e filhas na escola, fortalecimento dos estereótipos de que o feminino é mais inteligente, organizado, sensível, em detrimento de um masculino que deve proteger e manter

${ }^{5}$ Sociedade que é centrada na escrita. 
financeiramente as mulheres. Como bem lembra Carvalho (2003), o gênero é uma categoria que emerge das relações sociais, vinculada aos aspectos históricos e culturais das diferenças respaldadas no sexo.

Entretanto, essa singela preocupação dos(as) docentes já é um importante começo, considerando que, mesmo de forma parcial, sem maior aprofundamento dos processos que vão garantir 0 desenvolvimento de atividades pedagógicas que venham a criar nas escolas e nos CEJAs espaços de equidade, de desconstrução dessas diferenças entre os papéis impostos pela sociedade do que é ser homem ou mulher, as políticas educacionais trazem alguns apontamentos. O que parece é que falta um fortalecimento dessas discussões nos diversos espaços onde se desenvolvem processos educacionais, neste caso, voltados às especificidades da EJA.

Assim, as causas e os efeitos evidenciados nas análises realizadas têm a ver com a falta de uma proposta mais direta. Nessa situação, uma proposta curricular para o Ensino Médio da EJA seria o ideal para iniciar uma caminhada junto aos(às) profissionais envolvidos(as) nesse processo, em direção da visualização de como fazer, de como colocar essas ideias na prática nas diferentes áreas do conhecimento. Mas essa, por si só, não seria a resposta final e definitiva. O que está acontecendo é que no local da prática está havendo uma (re)interpretação das políticas, e não estão se encontrando meios para cumprir com o prescrito, o que vem gerando uma despreocupação ao invés de uma busca por ações reflexivas com poder de transformação da realidade posta.

Frente a isso, não se observam estratégias dos órgãos competentes para auxiliar esses(as) profissionais no desenvolvimento de um trabalho mais efetivo ${ }^{6}$ junto aos(às) discentes da EJA. Desse modo, tornam-se inoperantes os meios de produção de canais, por onde as mudanças poderiam vir a criar outras políticas assistenciais com poder de intervir nas dificuldades que emergem em meio às demandas dessa modalidade de ensino.

O conjunto de aspectos explicitados acima indica que, como nos estudos de Pereira (2009), o currículo é uma rede de significações, que ao longo do trajeto leva em consideração o tempo e espaço. Neste, promove a (re)significação, ou seja, produz novos sentidos das demandas sociais. Isto quer dizer que o deslocamento de um currículo nacional, centrado nos modelos da cultura dominante, deve se transformar em um currículo mais plural que contemple as culturas, os direitos humanos, éticos, emancipacionistas, inter e transdisciplinar etc. Por fim, esses diferentes discursos têm origem na sociedade (contextos) e nas agências políticas que criam as políticas (textos), o que torna relevante entender como os currículos na EJA vêm sendo ressignificados, a fim de trabalhar as relações de gênero, a partir das experiências dos sujeitos e das políticas curriculares.

\section{REFERÊNCIAS}

BALL, S. J. Education reform: a critical and post structural approach. Buckingham: Open University Press, 1994.

BOWE, R.; BALL, S. J.; GOLD, A. Reform in education \& changing schools: case studies in Policy Sociology. London: Routledge, 1992.

BRASIL. Documento nacional preparatório à VI Conferência Internacional de Educação de Adultos (VI CONFINTEA). Brasília: MEC; Goiânia: FUNAPE/UFG, 2009. Disponível em:

<http://portal.mec.gov.br/index.php?option=com_docman\&task=doc_download\&gid=10024\&ltemid=>. Acesso em: 2 abr. 2015.

. Lei $n^{\circ} 9.394$, de 20 de dezembro de 1996, que estabelece as diretrizes e bases da educação nacional. 9. ed. Brasília: Câmara dos Deputados, Edições Câmara, 2014.

. Resolução CNE/CEB n ${ }^{\circ}$, de 5 de julho de 2000, que estabelece as Diretrizes Curriculares Nacionais para a Educação e Jovens e Adultos. Disponível em:

\footnotetext{
6 Formação continuada pensando no contexto da EJA para os professores das diversas áreas do conhecimento. O que fortaleceria a construção de propostas pedagógicas que pudessem realmente refletir com a comunidade escolar sobre as problemáticas ligadas às relações e gênero e às várias outras formas de manutenção das relações de poder que podem emergir do currículo.
} 
ISSN 1983-1579

Doi: 10.22478/ufpb.1983-1579.2018v3n11.33465

http://periodicos.ufpb.br/ojs2/index.php

<http://portal.mec.gov.br/secad/arquivos/pdf/eja/legislacao/parecer_11_2000.pdf>. Acesso em: 22 abr. 2015 .

BUTLER, Judith. Deshacer el gênero. Buenos Aires: Paidos, 2006.

. Problemas de gênero: feminismo e subversão da identidade. Rio de Janeiro: Civilização Brasileira, 2003.

CARVALHO, M. E. P. O que a história tem a ver com as relações de gênero? Problematizando o gênero no currículo e na formação docente. In: CARVALHO, M. E. P.; PEREIRA, M. Z. C. (Org.). Gênero e Educação: múltiplas faces. João Pessoa: Editora Universitária/UFPB, 2003. p. 55-76.

FOUCAULT, Michel. Vigiar e Punir. 32. ed. Petrópolis: Vozes, 1987.

HADDAD, S.; DI PIERRO, Ma. Clara. Escolarização de jovens e adultos. Revista Brasileira de Educação, n. 14, p. 108-194, maio/ago. 2000.

LOPES, A. C. Relações macro/micro na pesquisa em currículo. Cadernos de Pesquisa, São Paulo, v. 36, n. 129, p. 619-635, set./dez. 2006.

; MACEDO, E. Contribuições de Stephen Ball para o estudo de Políticas de Currículo. In:

Políticas educacionais: questões e dilemas. São Paulo: Cortez, 2011.

MAINARDES, J. Abordagem do ciclo de políticas: uma contribuição para a análise de políticas educacionais. Educação \& Sociedade, Campinas, v. 27, n. 94, p. 47-69, jan./abr. 2006.

; STREMEL, S. Informações sobre a abordagem do ciclo de políticas. 2015. Disponível em:

<file://C:/Users/Rafael/Downloads/Abordagem\%20do\%20Ciclo\%20de\%2

oPoliticas_Stephen\%20J\%20Ball.pdf>. Acesso em: 05 set. 2015.

OLIVEIRA, A.; MATHEUS, D.; LOPES, A. C. Políticas de currículo: a luta pela significação no contexto da prática. In: FERRAÇO, Carlos Eduardo; GRABRIEL, Carmem Teresa; AMORIM, Antonio Carlos. Políticas de currículo e escola. Campinas, SP: FE/UNICAMP, 2011. p. 119-133.

OLIVEIRA, I. B.; PAIVA, J. (Org.). Educação de jovens e adultos. Rio de Janeiro: DP et alii, 2009.

OLIVEIRA, I. B.; TEIXEIRA, B. P.; CAMPOS, M. S. N.

Narrativas como prática emancipatória: pesquisando e repensando os currículos praticados naEJA. In: $P$ AIVA, J.; PINHEIRO, R. A. Da pesquisa em educação à pesquisa na EJA: ações

plurais, sentidos singulares. Natal, RN: EDUFRN, 2011. p. 17-37.

PAIVA, J. Os sentidos do direito à educação de jovens e adultos. Petrópolis/ RJ: FAPERJ, 2009.

PARAÍBA. Portaria $n^{\circ}$ 1.115, de 20 de novembro de 2014. Baixa instruções complementares para gestão de pessoal relativas ao ano letivo 2015 e dá outras providências. João Pessoa: Secretaria de Estado de Educação, 2014. Disponível em: <http://static.paraiba.pb.gov.br/2013/12/Diretrizes-Operacionais-SEE-PB2015.pdf $\geq$. Acesso em: 25 fev. 2015.

PARAISO, Marlucy Alves. Sistemas de raciocínios generificados no currículo escolar e possibilidades de aprender. In: COLÓQUIO SOBRE QUESTÕES CURRICULARES, IX; COLÓQUIO LUSO-BRASILEIRO, V, 2010. Porto. Anais... Porto, 2010.

PEREIRA, M. Z. C. Currículo, discurso e discursos. In: MACEDO, Elizabeth; MACEDO, Roberto Sidnei; AMORIM, Antônio Carlos (Org.). Discurso, texto, narrativa nas pesquisas em currículo. Campinas - SP: FE/UNICAMP, 2009. p. 114-123.

PROJETO POLÍTICO PEDAGÓGICO. João Pessoa: [s.n.], 2015.

VALE, E. C.; OLIVEIRA, I. B. A ressignificação da EJA, o currículo e a centralidade da cultura: da educação popular aos processos de escolarização. Trabalho apresentado no I Congresso Internacional da Cátedra UNESCO de Educação de Jovens e Adultos. João Pessoa, 2010. 
Recebido em: 23/03/2017

Alterações recebidas em: 11/09/2018

Aceito em: 05/11/2018 